\title{
A Conspicuous Pragmatic Scope to Influence Teaching Legal English to Algerian Students: The Case of Legal English Students at the Faculty of Law, University of Oran 2
}

\author{
Younes Saaid ${ }^{1} \&$ Mimouna Zitouni ${ }^{2}$ \\ ${ }^{1} \mathrm{PhD}$ student, Faculty of Foreign Languages, University of Oran 2, Algeria, \\ ${ }^{2}$ Associate Professor, Faculty of Foreign Languages, University of Oran 2, Algeria,
}

Abstract

Being able to use English in a proficient manner has undoubtedly become an essential asset in Algerian professional and academic settings over the last few years. Recent contingency for a better future for graduate and undergraduate Algerian students has generated willingness to acquire the needful skills to be ready to compete at the national and international market levels. In the case of Legal English, the development of vocabulary, reading, writing, speaking and listening skills requires the refitting and remodeling of the teaching approaches and practices to act in response to the students' present and future needs and expectations. Accordingly, teaching legal language should cover and infiltrate the study of specialized countenance in conjunction with scrupulous syntax of legal English which portrays long and complex sentences and syntactic discontinuities. Moreover, due to the fact that legal English is used in real professional settings, its pragmatic dimension is predominantly crucial. This research work spotlights the manner in which the pragmatic peculiar features of legal English could be taught to Algerian law students.

Keywords: Legal English, Context, Student Needs, Form and Function. 